\title{
Endomeatal approach in cochlear implant surgery in a patient with small mastoid cavity and procident lateral sinus
}

\author{
Francesco Galletti, Francesco Freni, Francesco Gazia, ${ }^{\circledR}$ Bruno Galletti
}

Department of Adult and Development Age Human Pathology "Gaetano Barresi", Unit of Otorhinolaryngology، Universita degli Studi di Messina, Messina, Italy

\section{Correspondence to} Dr Francesco Gazia, ssgazia@gmail.com

Accepted 21 May 2019

\section{DESCRIPTION}

Endomeatal approach (EMA) in cochlear implant (CI) surgery avoid mastoidectomy and posterior tympanotomy (PT) by using the external auditory canal (EAC) and the round window (RW) as a natural access pathway for CI positioning. ${ }^{1} \mathrm{We}$ present a modified technique for EMA applied in a 78-year-old patient with profound hearing loss and a history of diabetes and hypothyroidism. ${ }^{2}$ For several years, the patient has reported poor improvements through the use of an auricular prosthetic device. Our multidisciplinary team decided to undertake the procedure and perform a CI surgery in the ear with a worse auditory performance. The patient underwent vaccination for Streptococcus pneumoniae, Haemophilus influenzae and Neisseria meningitidis, and CT of the brain and MRI have been performed. The instrumental diagnosis displayed the presence of a small mastoid cavity and a bilateral procident lateral sinus. ${ }^{4}$

Given the radiological objective, it was decided to perform CI surgery with an EMA, whose surgical steps are detailed on video (Video 1).

A month after the surgery, CI was correctly activated, with no signs of postsurgical complications being displayed. The patient showed an excellent capacity for social interaction and a great fitting of the implant.

The incidence of facial nerve lesions following PT - which are mainly caused by direct injury or heat produced by drilling - has been reported to be $1 \% .^{5}$ The visualisation of the facial channel over the platina of the stape provided a safely controlled technique to ensure a healthy formation of the groove and avoid the occurrence of alterations to

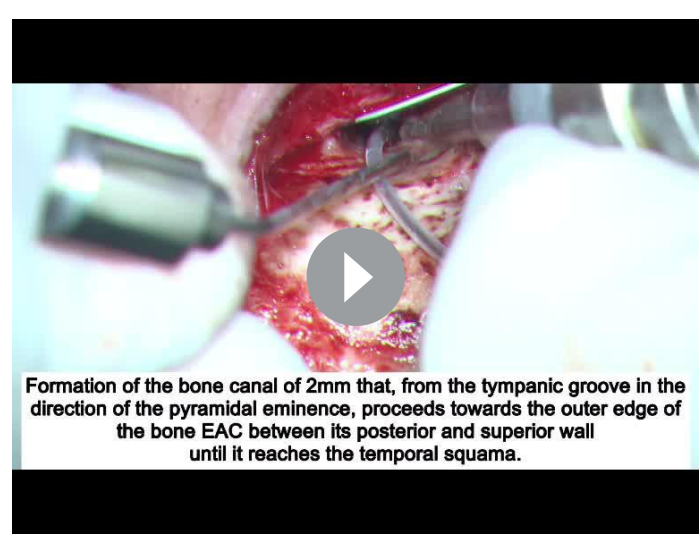

Video 1 Surgery steps in endomeatal approach in cochlear implant collocation the facial nerve-located in the posterior EAC wall. Thanks to mobilisation of the incus, we are sure to maintain the facial nerve intact.

The main advantages of this technique compared with the traditional mastoidectomy and PT are recognised as follows:

A faster better access to the scala tympani.

A wider electrode insertion angle.

A decreased risk for the groove formation to damage the facial nerve, as it is placed in the posterior EAC wall, which is distant to the nerve.

Avoidance of cholesteatoma and middle ear infections since only a small segment of the electrode array resides in the middle ear space, and no mastoid cavity is present.

A drastic reduction in the risk for the electrode to get in contact with the skin and the extrusion, as the bone paté is enough to support the electrode inside the groove.

EMA discourages false pathways and increases stimulation of the neuronal population by placing the basal electrodes at the onset of the scala tympani.

EMA is a soft surgery technique that facilitates CI collocation in alterations of classical anatomy, such as anteriorly located facial nerve, procident lateral sinus, narrow facial recess and small mastoid cavity.

Given the excellent result of our case and the possibility for this technique to be used on craniofacial malformations, we deem EMA to be an effective, safe and minimally invasive technique even in anatomically varying cases affecting the ear.

\section{Learning points}

Endomeatal approach (EMA) in cochlear implant surgery should be the gold standard in anatomically varying cases, such as procident lateral sinus and small mastoid cavity.

- The changes made to the traditional EMA allow a better preservation of the facial nerve and a lower occurrence of dislocation of the array.

Contributors FGal was the first surgeon. BG and FF were the assistants. FGaz made the video and prepared the manuscript.

Funding The authors have not declared a specific grant for this research from any funding agency in the public, commercial or not-for-profit sectors.

Competing interests None declared. 
Images in...

Patient consent for publication Obtained.

Provenance and peer review Not commissioned; externally peer reviewed.

\section{REFERENCES}

1 Slavutsky V, Nicenboim L. Preliminary results in cochlear implant surgery without antromastoidectomy and with atraumatic electrode insertion: the endomeatal approach. Eur Arch Otorhinolaryngol 2009:266:481-8
2 Freni F, Galletti B, Galletti F, et al. Improved outcomes for papillary thyroid microcarcinoma care: active surveillance and case volume. Ther Adv Endocrinol Metab 2018;9:185-6.

3 Galletti B, Bruno R, Catalano N, et al. Follicular carcinoma on a radio-treated ectopic lingual thyroid. Chirurgia 2016;29:88-91.

4 Ciodaro F, Freni F, Mannella VK, et al. Use of 3D Volume Rendering Based on HighResolution Computed Tomography Temporal Bone in Patients with Cochlear Implants. Am J Case Rep 2019:20:184-8.

5 El-Anwar MW, ElAassar AS, Foad YA. Non-mastoidectomy Cochlear Implant Approaches: A Literature Review. Int Arch Otorhinolaryngol 2016;20:180-4.

Copyright 2019 BMJ Publishing Group. All rights reserved. For permission to reuse any of this content visit https://www.bmj.com/company/products-services/rights-and-licensing/permissions/

BMJ Case Report Fellows may re-use this article for personal use and teaching without any further permission.

Become a Fellow of BMJ Case Reports today and you can:

- Submit as many cases as you like

- Enjoy fast sympathetic peer review and rapid publication of accepted articles

- Access all the published articles

- Re-use any of the published material for personal use and teaching without further permission

\section{Customer Service}

If you have any further queries about your subscription, please contact our customer services team on +44 (0) 2071111105 or via email at support@bmj.com.

Visit casereports.bmj.com for more articles like this and to become a Fellow 